\title{
Mechanical Resilience of Modified Bitumen at Different Cooling Rates: A Rheological and Atomic Force Microscopy Investigation
}

\author{
Cesare Oliviero Rossi ${ }^{1, *}$, Saltanat Ashimova ${ }^{1,2}$, Pietro Calandra ${ }^{3}$, Maria Penelope De Santo ${ }^{4}$ \\ and Ruggero Angelico $5,6, *$ \\ 1 Department of Chemistry and Chemical Technologies, University of Calabria, \\ 87036 Arcavacata di Rende (CS), Italy; salta_32@mail.ru \\ 2 Kazakhstan Highway Research Institute, Nurpeisova Str., 2A, Almaty 050061, Kazakhstan \\ 3 CNR-ISMN, National Council of Research, Via Salaria km 29.300, 00015 Monterotondo Stazione (RM), Italy; \\ pietro.calandra@ismn.cnr.it \\ 4 Department of Physics and CNR-Nanotec, University of Calabria, 87036 Rende (CS), Italy; \\ maria.desanto@fis.unical.it \\ 5 Department of Agricultural, Environmental and Food Sciences (DIAAA), University of Molise, \\ Via De Sanctis, 86100 Campobasso (CB), Italy \\ 6 CSGI (Center for Colloid and Surface Science), Via della Lastruccia 3, I-50019 Sesto Fiorentino (FI), Italy \\ * Correspondence: cesare.oliviero@unical.it (C.O.R.); angelico@unimol.it (R.A.); \\ Tel./Fax: +39-0984-492045 (C.O.R.); +39-0874-404649 (R.A.)
}

Received: 8 July 2017; Accepted: 28 July 2017; Published: 31 July 2017

\begin{abstract}
Due to the wide variation in geographic and climatic conditions, the search for high-performance bituminous materials is becoming more and more urgent to increase the useful life of pavements and reduce the enormous cost of road maintenance. Extensive research has been done by testing various bitumen modifiers, although most of them are petroleum-derived additives, such as polymers, rubbers and plastic, which in turn do not prevent oxidative aging of the binder. Thus, as an alternative to the most common polymeric rheological modifiers, selected binder additives falling in the categories of organosilane (P2KA), polyphosphoric acid (PPA) and food grade phospholipids (LCS) were homogeneously mixed to a base bitumen. The goal was to analyse the micro-morphology of the bitumens (neat and modified) subjected to different cooling rates and to find the corresponding correlations in the mechanical response domain. Therefore, microstructural investigations carried out by Atomic Force Microscopy (AFM) and fundamental rheological tests based on oscillatory dynamic rheology, were used to evaluate the effect of additives on the bitumen structure and compared with pristine binder as a reference. The tested bitumen additives have been shown to elicit different mechanical behaviours by varying the cooling rate. By comparing rheological data, analysed in the framework of the "weak gel" model, and AFM images, it was found that both P2KA and PPA altered the material structure in a different manner whereas LCS revealed superior performances, acting as "mechanical buffer" in the whole explored range of cooling rates.
\end{abstract}

Keywords: modified bitumen; Atomic Force Microscopy; Dynamic Oscillatory Rheology; complex modulus; "weak gel" model

\section{Introduction}

In today's road construction technology, the demand for bitumen characterised by high mechanical properties becomes increasingly insistent, even if it represents only a minor component of asphalt (5-8\% by weight of binder) [1]. 
Bitumen, which is a complex solid or semisolid colloidal dispersion of asphaltenes into a continuous oily phase constituted by saturated paraffins, aromatics and resins [2-4], is a viscoelastic material whose mechanical response is both time and temperature dependent [5]. However, because of the wide variation in geographical and climatic conditions, a careful selection of bituminous materials is required to increase the useful life of the pavement and reduce the huge cost of road maintenance. For instance, for a good road performance, it would be highly desirable that the deformation properties of bitumen remain unchanged under the effect of different cooling rates, and mitigate the susceptibility of asphalt concrete to several drawbacks such as thermal cracking and thermal stress accumulation [6]. Indeed, depending on the geographical areas, the bitumen used in hot-mix asphalt concretes for road construction may suffer severe thermal shocks during placement of the asphalt top layer onto pavements, characterised by a wide range of surface temperatures $[7,8]$. Therefore, to facilitate the evaluation of cooling rate sensitivity in controlled lab-scale conditions, the temperature of both pristine bitumen and bitumen modified with three additives was varied from $105^{\circ} \mathrm{C}$ to $25^{\circ} \mathrm{C}$ using cooling rates of 1,5 and $10^{\circ} \mathrm{C} / \mathrm{min}$, respectively. Being aware that the selected cooling rates might not exactly reproduce the realistic pavement conditions met in a field study, the purpose of this analysis was to gain a preliminary understanding of the impact that additives distinct from the most common polymers [9-11] may have on the bitumen rheological response to changes in the cooling rate. Therefore, a rheological investigation was performed to compare the mechanical behaviour manifested by a base bitumen modified with three additives, namely, organosilane (P2KA), polyphosphoric acid (PPA) and food grade phospholipids (LCS), whose properties as rheological/adhesion bitumen modifiers have been widely investigated [12-15]. Specifically, oscillatory rheological tests were carried out to monitor the dependence of complex mechanical modulus on the type of additive at various cooling rates. According to the present research project, we seek the most efficient additive that would make the mechanical modulus of the correspondent modified bitumen less temperature-sensitive in the explored cooling ramp range. A parallel structural investigation by using Atomic Force Microscopy (AFM) has been also undertaken at $25^{\circ} \mathrm{C}$ to monitor changes in the micro-morphology of both virgin and modified bitumens once subjected to different cooling rates. Indeed, previous AFM investigations were found successful in studying the bitumen microstructure at nanoscale level, including its surface morphology dependence on various physico-chemical parameters [16-18]. Therefore, the results illustrated in the present study and obtained from a combination of oscillatory rheology and AFM measurements have been found very useful in the identification of the best additive able to leave the bituminous structure nearly unaffected by the action of different cooling rates applied in range of $1-10{ }^{\circ} \mathrm{C} / \mathrm{min}$.

\section{Materials and Methods}

\subsection{Materials}

The asphalt binder was kindly supplied by Loprete Costruzioni Stradali (Terranova Sappo Minulio, Calabria, Italy) and was used as base bitumen. It was produced in Italy and the crude oil was from Saudi Arabia. The neat bitumen was modified by adding commercial additives, namely, (a) phospholipids in the form of light yellow powder (hereafter LCS) provided by Somercom srl (Catania, Italy); (b) organosilane P2KA provided by KimiCal s.r.l. (Rende, Italy) and (c) polyphosphoric acid (PPA) provided by Sigma Aldrich (Milano, Italy).

\subsection{Sample Preparations and Setup of Cooling Ramps}

The additives were mixed separately to hot bitumen $\left(140-160^{\circ} \mathrm{C}\right)$ at fixed content of $2 \% \mathrm{wt} / \mathrm{wt}$ [12-14] by using a mechanical stirrer (IKA RW20, Königswinter, Germany). First, $100 \mathrm{~g}$ of bitumen was heated up to $140-160{ }^{\circ} \mathrm{C}$ until it flowed fully, then a given amount of additive was added to the melted bitumen under a high-speed shear mixer at 500-700 rpm. Furthermore, the mixtures were stirred again at $140-160^{\circ} \mathrm{C}$ for $30 \mathrm{~min}$. After mixing, three different cooling ramp rates were applied to bitumen 
samples modified with P2KA, PPA and LCS, respectively. Parallel temperature ramp tests were carried out on unmodified bitumen as a reference system. The experimental conditions were isothermal annealing for $10 \mathrm{~min}$ at $160^{\circ} \mathrm{C}$ then cooling at 1,5 and $10^{\circ} \mathrm{C} / \mathrm{min}$ until room temperature was reached.

\subsection{SARA Determination}

The Iatroscan MK 5 Thin Layer Chromatography (TLC) was used for the chemical characterisation of bitumen by separating it into four fractions: Saturates, Aromatics, Resins and Asphaltenes (SARA) [19]. During the measurement, the separation took place on the surface of silica-coated rods. The detection of the amount of different groups was according to the flame ionisation. The sample was dissolved in peroxide-free tetrahydrofurane solvent to reach a $2 \%(w / v)$ solution. Saturated components of the sample were developed in $n$-heptane solvent while the aromatics were developed in a 4:1 mixture of toluene and $n$-heptane. Afterwards, the rods had to be dipped into a third tank, which was a 95 to $5 \%$ mixture of dichloromethane and methanol. That organic medium proved suitable to develop the resin fraction whereas the asphaltene fraction was left on the lower end of the rods. Details of bitumen composition are listed in Table 1.

Table 1. Group composition of the tested neat bitumen.

\begin{tabular}{cc}
\hline SAMPLE & SARA Fraction in Weight $\mathbf{\%}( \pm \mathbf{0 . 1})$ \\
\hline Saturated & 4.2 \\
Aromatics & 51.6 \\
Resins & 21.3 \\
Asphaltenes & 22.9 \\
\hline
\end{tabular}

\subsection{Empirical Characterisation}

Penetration tests for bitumens were performed according to the standard procedure (ASTM D946) [20]. The bitumen consistency was evaluated by measuring the penetration depth (531/2-T101, Tecnotest, Castelfranco, Treviso, Italy) of a stainless steel needle of standard dimensions under determinate charge conditions $(100 \mathrm{~g})$, time $(5 \mathrm{~s})$ and temperature $\left(25^{\circ} \mathrm{C}\right)$.

\subsection{AFM Microstructure Analysis}

Atomic Force Microscopy equipment (Multimode VIII with a Nanoscope V controller, Bruker, Karlsruhe, Germany) was used to analyse the samples. The AFM was used in tapping mode, where the cantilever oscillates up and down close to its resonance frequency so that the tip contacts the sample surface intermittently. When the tip is brought close to the surface, the vibration of the cantilever is influenced by the tip-sample interaction. In particular, shifts in the phase angle of vibration of the cantilever are due to the energy dissipation in the tip-sample ensemble. The phase shift provides information on surface properties such as stiffness, viscoelasticity and adhesion. For measurements, Antimony-doped silicon probes (TAP150A, Bruker) with resonance frequency $150 \mathrm{kHz}$ and nominal tip radius of curvature $10 \mathrm{~nm}$ were used. All the measurements were performed at room temperature. Phase images were acquired simultaneously with the topographic mode. Materials with different viscoelasticity were clearly distinguishable. The softer domains appeared dark while the stiffer ones appeared bright in the phase images (see Figure 1A-H).

\subsection{Isothermal Rheological Tests after Different Cooling Ramps}

After each cooling ramp, samples were subjected to oscillatory rheological tests at constant temperature $t=25^{\circ} \mathrm{C}$, controlled by a Peltier element $\left( \pm 0.1^{\circ} \mathrm{C}\right)$, using a dynamic stress-controlled rheometer (SR5, Rheometric Scientific, Piscataway, NJ, USA) equipped with a parallel plate geometry (gap $2.0 \pm 0.1 \mathrm{~mm}$, diameter $25 \mathrm{~mm}$ ). The linear viscoelastic regime of both neat and modified bitumens was checked through the determination of the complex shear modulus $G^{*}(\omega)$ in the regime 
of small-amplitude oscillatory shear $[21,22]$. $G^{*}(\omega)$ can be considered the sample's total resistance to deformation when repeatedly sheared. For viscoelastic materials, $G^{*}(\omega)$ is split into a real and an imaginary part, respectively, [23]:

$$
\mathrm{G}^{*}(w)=\mathrm{G}^{\prime}(\omega)+i \mathrm{G}^{\prime \prime}(w)
$$

The frequency-dependent functions $G^{\prime}(\omega)$ and $G^{\prime \prime}(\omega)$ define the in-phase (storage) and the out-of-phase (loss) moduli, respectively, $i$ being the imaginary unit of the complex number. $G^{\prime}(\omega)$ is a measure of the reversible, elastic energy, while $G^{\prime \prime}(\omega)$ represents the irreversible viscous dissipation of the mechanical energy [24]. Both the storage and loss moduli are related to each other through the phase angle $\delta$ defined by:

$$
\tan \delta=G^{\prime \prime}(\omega) / G^{\prime}(\omega)
$$

Aimed at investigating the material structure, frequency sweep tests were performed at $25{ }^{\circ} \mathrm{C}$ and proper stress values were applied to guarantee linear viscoelastic conditions.

\section{Results and Discussion}

Bitumen was characterised by the SARA method and four different groups were individuated: Saturates, Aromatics, Resins and Asphaltenes (SARA). We recall here that according to the current accepted colloidal model for bitumen, asphaltene molecules rich in resins as peptizing agents self-assembly into micellar-like structures dispersed into the continuous phase composed mainly by the saturated and aromatic oil fractions (maltene) [25-27]. The SARA content of the pristine bitumen was determined (see Section 2) and the results are shown in Table 1.

\subsection{AFM Results}

Both neat and modified bitumens have been studied in micro-scale at room temperature (RT) after being subjected to different cooling rates. Figure 1 collects AFM phase images acquired after the tested specimens had been slowly cooled at $1{ }^{\circ} \mathrm{C} / \mathrm{min}$ from $105^{\circ} \mathrm{C}$ to $\mathrm{RT}$ (Figure $1 \mathrm{~A}, \mathrm{C}, \mathrm{E}, \mathrm{G}$ ) and compared to an analogous series of images from the same samples subjected to a faster cooling ramp at $10^{\circ} \mathrm{C} / \mathrm{min}$ (Figure 1B,D,F,H). A first effect of cooling rate can be observed on the unmodified bitumen where coarse and isolated aggregates (which form the catana-phase $[16,28]$ ), with irregular or ellipsoid shaped domains dispersed into maltene matrix, are replaced by smaller oblong shaped structures with a rippled interior (1A vs. 1B). The occurrence of those discrete domains has been attributed to the crystallisation process of the paraffin wax fraction $[16-18,29]$ where the formation of small crystalline nuclei may be kinetically favoured with respect to the particle growth process if bitumen undergoes too fast cooling rates [30]. A more dramatic micro-morphology change can be observed when the organosilane additive (P2KA) is added to the base bitumen (1C vs. 1D). After a slow cooling ramp temperature $\left(1^{\circ} \mathrm{C} / \mathrm{min}, 1 \mathrm{C}\right)$, a rough surface morphology has been imaged at $\mathrm{RT}$, constituted by irregular often-interlocking domains. As the sample is cooled at a faster rate $\left(10^{\circ} \mathrm{C} / \mathrm{min}, 1 \mathrm{D}\right)$, the phase-contrast images reveal several small submicrometer crystalline structures resembling the 'ant-like' spots observed by Ramm et al. [31], considered as metastable aggregates subjected to a kinetic rather than thermodynamic control. 


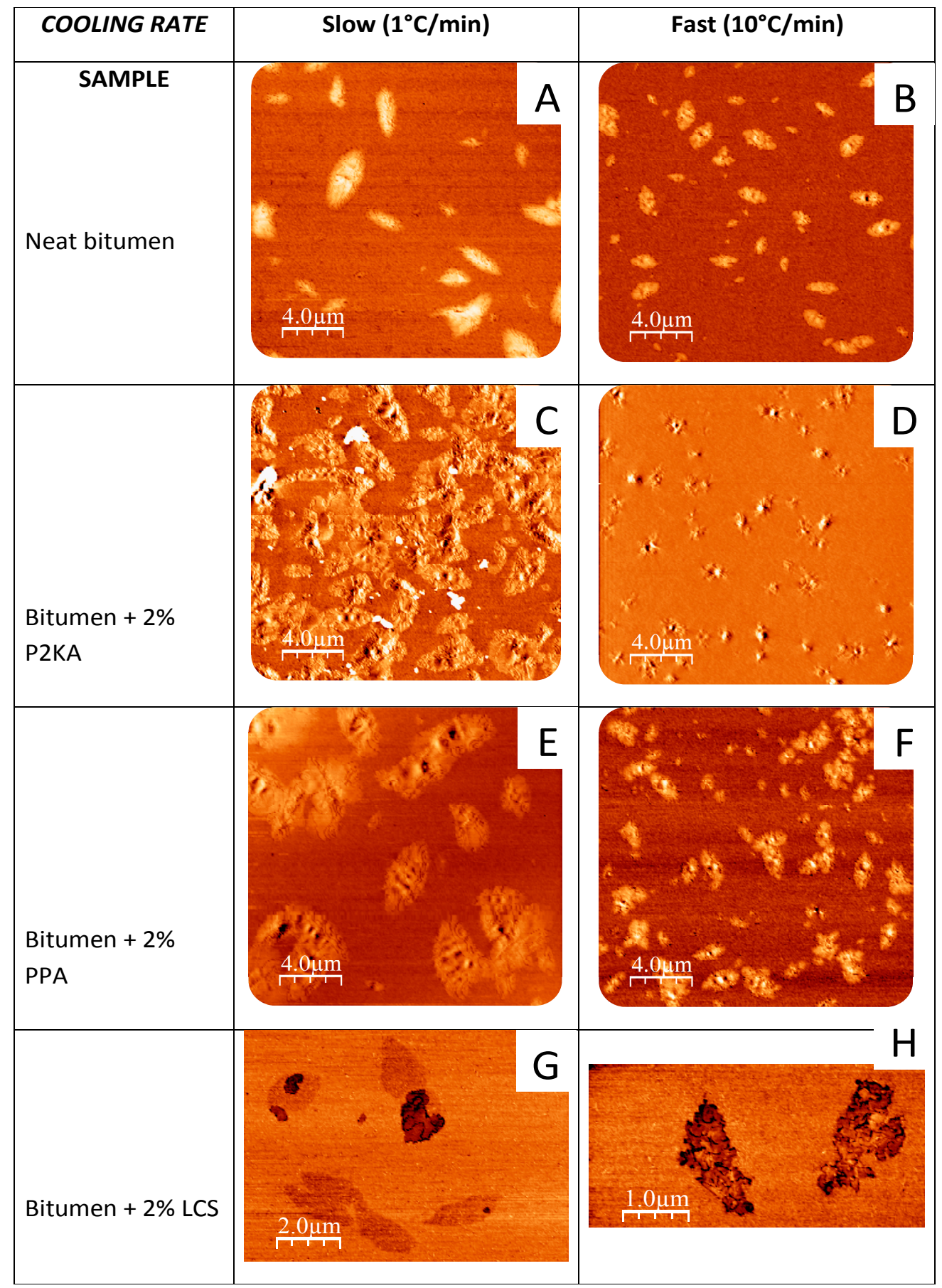

Figure 1. Atomic Force Microscopy (AFM) phase images at room temperature (RT) of both neat bitumen and bitumens modified by addition of $\%$ P2KA, PPA and LCS, respectively. The microphotographs were acquired after different thermal treatments: slowly cooled at $1{ }^{\circ} \mathrm{C} / \mathrm{min}$ to $\mathrm{RT}(\mathbf{A}, \mathbf{C}, \mathbf{E}, \mathbf{G})$ and quickly cooled at $10^{\circ} \mathrm{C} / \mathrm{min}$ to $\mathrm{RT}(\mathbf{B}, \mathbf{D}, \mathbf{F}, \mathbf{H})$.

Addition of polyphosphoric acid (PPA) gives rise to surface structuring very similar to pristine bitumen. Indeed, after a slow cooling rate, large pseudo-spherical or lenticular domains have been imaged (1E) characterised by catana-phase with transverse stripes of high and low surface height surrounded by peri-phase regions; likewise, it has been observed in analogous AFM studies [18,32]. However, after subjecting the bitumen to rapid cooling treatments, smaller crystallites with irregular or ellipsoidal shapes are formed, yet retaining the same inner rippled microstructure $(1 \mathrm{~F})$. 
A completely different scenario has been found for bitumen modified with $2 \mathrm{wt} \%$ of phospholipids (LCS). Indeed, irregular domains with low phase contrast coexist with fractal-like and more defined particles with similar average dimensions. Those micro-morphological features have been found unaffected by the different cooling ramps applied to LCS-modified bitumen, as can be easily verified by comparing the AFM phase images acquired after slow cooling (1G) and fast cooling $(1 \mathrm{H})$ rates, respectively. During the investigation of LCS samples, the contact between the tip and the sample was unstable, due to the large attractive forces caused by the probable presence of LCS even on the sample surface, and this led to difficulties in imaging large areas. The measurements were, then, performed on small areas in order to visualise the single domain's size.

It is worth noting that the apparent aggregates' invariance detected at microstructural level regardless of the chosen ramp is reflected also by a correspondent mechanical resilience manifested by LCS-modified bitumen, as will be described in more details in the next paragraph.

\subsection{Oscillatory Shear Experiments}

The viscoelastic properties of bitumens were analysed by oscillatory experiments (frequency-sweeps and temperature sweeps) at $25{ }^{\circ} \mathrm{C}$. Preliminary stress-sweep tests were also performed by applying small strain amplitudes in order to define linear viscoelastic conditions. The frequency dependence of the experimental complex modulus $\left|\mathrm{G}^{*}\right|$ measured at $25^{\circ} \mathrm{C}$ for both unmodified and modified bitumens is illustrated in Figure 2 in correspondence to different thermal cooling gradients of, respectively, $1^{\circ} \mathrm{C} / \mathrm{min}(\mathrm{A}), 5^{\circ} \mathrm{C} / \mathrm{min}(\mathrm{B})$ and $10^{\circ} \mathrm{C} / \mathrm{min}(\mathrm{C})$.

Clear evidence can first be observed at low rates $\left(1^{\circ} / \mathrm{min}\right)$ and fast $\left(10^{\circ} / \mathrm{min}\right)$, showing substantial differences of $\left|G^{*}\right|$ among the various samples, attributable to the presence of the additives (see Figure 2A,C). An exception can be found for P2KA and PPA modified bitumens, characterised by $\left|G^{*}\right|$ data, which are almost overlapped for $1^{\circ} \mathrm{C} / \mathrm{min}$ (Figure 2A). However, the effect of the additives seems to be cancelled out at the intermediate cooling rate of $5{ }^{\circ} \mathrm{C} / \mathrm{min}$, where the respective rheological behaviours are hardly distinguishable from those of neat bitumen (see Figure 2B). As observed from AFM images, the development of amorphous/crystalline polydomains in the bitumens is controlled by nucleation and growth rates of disperse catana/peri-phase induced by different cooling rates, which in turn are affected also by the presence of additives. It should be expected that upon rapid cooling small aggregates would engender the formation of a network stabilised by physical interactions with a consequent increase of complex modulus $\left|G^{*}\right|$. To understand whether the added compounds are somewhat engaged in the formation of noncovalent interactions between asphaltene aggregates able to stabilise or even destabilise supramolecular networks upon cooling, the rheological data have been analysed in the framework of the colloidal gel model.

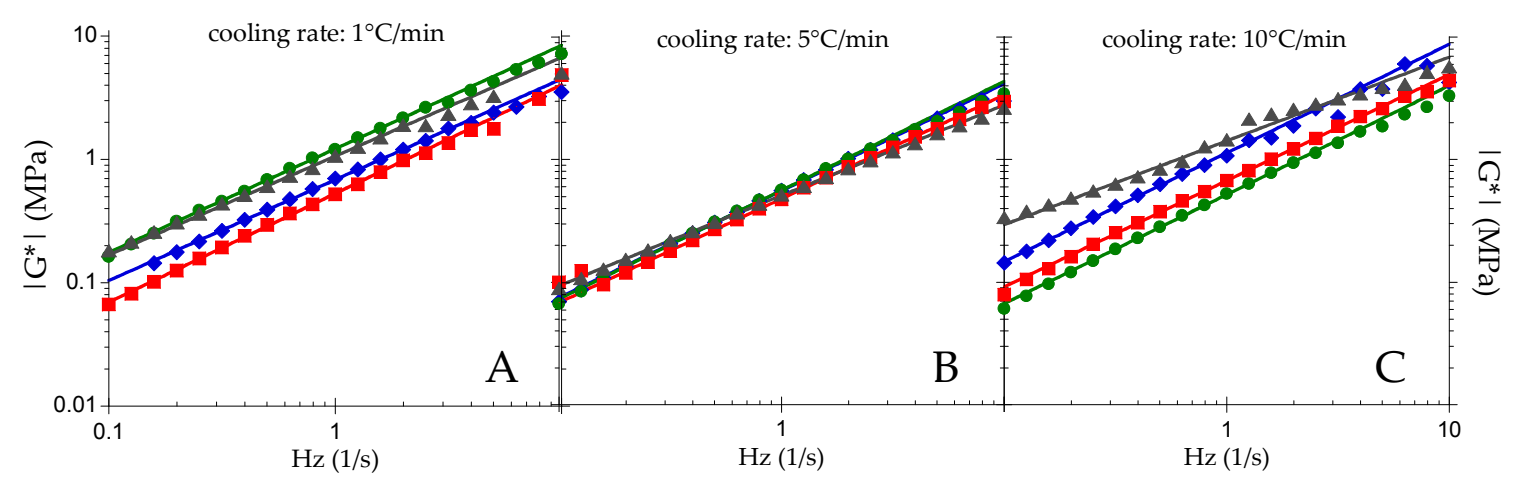

Figure 2. Complex modulus $\left|\mathrm{G}^{*}\right|$ vs frequency determined at $25^{\circ} \mathrm{C}$ for neat bitumen (diamonds), and bitumens modified by addition of $2 \%$ P2KA (circles), LCS (squares) and PPA (triangles), respectively, after the specimens were subjected to different thermal treatment: (A) $1{ }^{\circ} \mathrm{C} / \mathrm{min},(B) 5^{\circ} \mathrm{C} / \mathrm{min}$ and $(\mathbf{C})$ $10^{\circ} \mathrm{C} / \mathrm{min}$. Solid lines represent the best non-linear fits according to the power law of Equation (3), whose fitting parameters $z$ and $A$ have been listed in Tables 2 and 3, respectively. 
According to the theory of Bohlin [33] and Winter [34], which has been applied to several colloidal complex systems [35-37] and widely reported in literature as the "weak-gel model" [38], a weak-gel material is defined as a complex system characterised by a cooperative arrangement of flow units connected by weak physical interactions that cooperatively ensure the stability of the structure. Thus, the weak-gel model provides a direct link between the microstructure of the material and its rheological properties. The most important parameter is the "coordination number", $z$, which is the number of flow units interacting with each other to give the observed flow response. It was shown in reference [33] that, above the Newtonian region, there exists a regime characterised by the following flow equation:

$$
\left|G^{*}(\omega)\right|=\sqrt{G^{\prime}(\omega)^{2}+G^{\prime \prime}(\omega)^{2}}=A \omega^{\frac{1}{z}}
$$

where $A$ is a proper constant related to the overall stiffness or resistance to deformation of the material within the linear viscoelastic region at an angular frequency of $1 \mathrm{rad} / \mathrm{s}$. Clearly, a log-log plots of $\left|\mathrm{G}^{*}\right|$ vs. frequency should yield a straight line with slope $1 / z$ and intercept $A$.

In Tables 2 and 3, the parameters $z$ and $A$, calculated from non-linear fitting of viscoelastic data to Equation (1), are listed for all investigated samples subjected to different cooling rates. Three systems out of four, namely, neat bitumen and bitumens modified with P2KA and LCS, share a similar $z$ variability in the narrow range 1.12-1.22, confirming the presence of interacting asphaltenes that form lightly entangled networks. On the contrary, PPA shows a slightly higher flow coordination number, especially in the range $5-10{ }^{\circ} \mathrm{C} / \mathrm{min}$, evidencing its network-promoting effect, according to previous investigations $[39,40]$. In any case, the calculated $z$ values indicate that the coordination numbers are slightly affected by the thermal history as evidenced by the upper plot in Figure 3. A more useful parameter is represented by the constant prefactor of Equation (1) characterising the "interaction strength" of the three-dimensional structure of a gel, which is very sensitive to the cooling rates. Interestingly, an initial decrement of $A$ is observed for all the tested specimens in correspondence of the increment $1{ }^{\circ} \mathrm{C} / \mathrm{min} \rightarrow 5^{\circ} \mathrm{C} / \mathrm{min}$ in the cooling rate. Upon further increase to $10^{\circ} \mathrm{C} / \mathrm{min}$, both neat and PPA-modified bitumen show an upturn in $A$ whereas P2KA and LCS give rise to a minor change of $A$ (see the lower plot in Figure 3). What is worthy to remark here is that addition of LCS to bitumen provides the smallest $A$-variation within the explored range of cooling rates and this indicates that overall LCS is able to mitigate the effects provoked by a wide range of thermal gradients. The addition of LCS, whose adhesion efficiency has been recently ascertained [41], precludes the growth of nuclei formed during the nucleation stage, thus making the bulk bitumen structure almost unperturbed by drastic temperature variations.

Table 2. Dependence of the coordination number $z$ on the cooling rate, calculated as a fitting parameter in Equation (1) adapted to experimental oscillatory rheological data, $\left|G^{*}\right|$ vs. frequency, for neat bitumen and bitumens modified with additives.

\begin{tabular}{cccc}
\hline Cooling Rate $\left({ }^{\circ} \mathbf{C} / \mathbf{m i n}\right)$ & $\mathbf{1}$ & $\mathbf{5}$ & $\mathbf{1 0}$ \\
\hline Sample & $z$ & $z$ & $z$ \\
Bitumen & $1.22 \pm 0.01$ & $1.15 \pm 0.01$ & $1.13 \pm 0.03$ \\
Bitumen + P2KA 2\% & $1.19 \pm 0.01$ & $1.13 \pm 0.01$ & $1.12 \pm 0.01$ \\
Bitumen + LCS 2\% & $1.13 \pm 0.01$ & $1.18 \pm 0.01$ & $1.15 \pm 0.01$ \\
Bitumen + PPA 2\% & $1.25 \pm 0.02$ & $1.36 \pm 0.01$ & $1.46 \pm 0.06$ \\
\hline
\end{tabular}


Table 3. Dependence of the "interaction strength" $A$ on the cooling rate, calculated as a fitting parameter in Equation (1) adapted to experimental oscillatory rheological data, $\left|G^{*}\right|$ vs. frequency, for neat bitumen and bitumens modified with additives.

\begin{tabular}{cccc}
\hline Cooling Rate $\left({ }^{\circ} \mathrm{C} / \mathbf{m i n}\right)$ & $\mathbf{1}$ & $\mathbf{5}$ & $\mathbf{1 0}$ \\
\hline Sample & $A \times 10^{-6}$ & $A \times 10^{-6}$ & $A \times 10^{-6}$ \\
Bitumen & $0.68 \pm 0.01$ & $0.558 \pm 1 \times 10^{-3}$ & $1.14 \pm 0.01$ \\
Bitumen + P2KA 2\% & $1.22 \pm 0.01$ & $0.563 \pm 3 \times 10^{-3}$ & $0.518 \pm 2 \times 10^{-3}$ \\
Bitumen + LCS 2\% & $0.530 \pm 3 \times 10^{-3}$ & $0.479 \pm 2 \times 10^{-3}$ & $0.675 \pm 2 \times 10^{-3}$ \\
Bitumen + PPA 2\% & $1.06 \pm 0.01$ & $0.511 \pm 1 \times 10^{-3}$ & $1.42 \pm 0.03$ \\
\hline
\end{tabular}

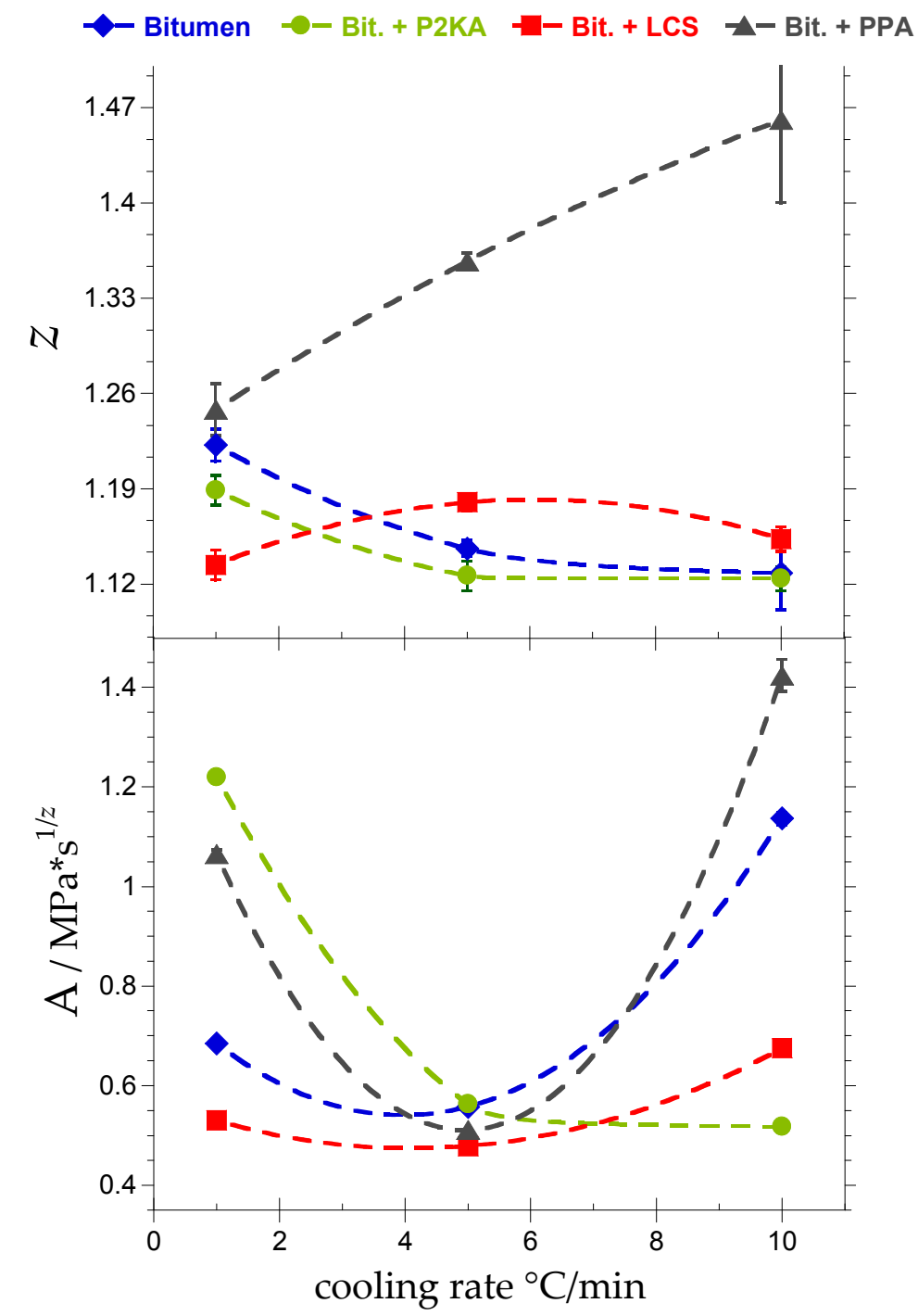

Figure 3. Dependence on the cooling rate of both $z$ coordination number (upper plot) and interaction strength A (lower plot) for neat bitumen (diamonds) and bitumens modified by addition of $2 \%$ P2KA (circles), LCS (squares) and PPA (triangles), respectively.

\section{Conclusions}

A comparative investigation of the mechanical responses manifested by bitumen modified with three non-polymeric additives was performed at $25{ }^{\circ} \mathrm{C}$, after the corresponding specimens were subjected to different cooling rates in the range $1-10^{\circ} \mathrm{C} / \mathrm{min}$. The selected range of cooling ramps 
represented a good compromise between suitable experimental conditions performed at lab-scale and hypothetical cooling events that might occur in realistic environmental conditions.

Aimed at searching for microstructural differences between various types of modified bitumens when they have undergone the action of several thermal ramps, a parallel morphological investigation was also carried out by using Atomic Force Microscopy (AFM). The correspondent rheological response was interpreted under the framework of the "weak gel" model whose analysis revealed the presence of lightly entangled networks with the exception of PPA-modified bitumen. A striking result was recorded from bitumen incorporating a raw mixture of natural phospholipids ( $2 \%$ LCS additive), which was able to leave the asphaltene aggregates fairly unaltered after the hot material was either slowly $\left(1^{\circ} \mathrm{C} / \mathrm{min}\right)$ or rapidly $\left(10^{\circ} \mathrm{C} / \mathrm{min}\right)$ cooled to the final reference temperature of $25^{\circ} \mathrm{C}$. The complex modulus of the correspondent LCS-modified bitumen was found almost independent of the cooling rate as well. The addition of LCS to bitumen should prove extremely fruitful in increasing the mechanical resistance of bitumen to thermal shocks and provide an attempt to substitute polymer-based rheology modifiers with additives derived from renewable bio-resources.

Acknowledgments: This work was financially supported by KimiCal s.r.l. (Rende, Italy). Authors were very grateful to Loprete SRL for the support offered (supply of bitumen) and Ing. G. Lo Prete who stimulated the need to undertake the present study with strong applicative implications.

Author Contributions: Cesare Oliviero Rossi and Ruggero Angelico conceived and designed the experiments; Maria Penelope De Santo performed the AFM experiments; Saltanat Ashimova prepared the samples and performed the rheological experiments; Pietro Calandra analyzed the data.

Conflicts of Interest: The authors declare no conflict of interest

\section{References}

1. Briscoe, O.E. Asphalt Rheology: Relationship to Mixture; ASTM Spec. Publ. 941; American Society for Testing and Materials: Philadelphia, PA, USA, 1987.

2. Yen, T.F.; Chilingarian, G.V. Asphalthenes and Asphalts; Elsevier: New York, NY, USA, 1994.

3. Rozeveld, S.; Shin, E.; Bhurke, A.; France, L.; Drzal, L. Network morphology of straight and polymer modified asphalt cements. Microsc. Res. Tech. 1997, 38, 529-543. [CrossRef]

4. Lesueur, D. The colloidal structure of bitumen: Consequences on the rheology and on the mechanisms of bitumen modification. Adv. Colloid Int. Sci. 2009, 145, 42-82. [CrossRef] [PubMed]

5. Loeber, L.; Muller, G.; Morel, J.; Sutton, O. Bitumen in colloid science: A chemical, structure and rheological approach. Fuel 1998, 77, 1443-1450. [CrossRef]

6. Apeagyei, A.K.; Dave, E.V.; Buttlar, W.G. Effect of Cooling Rate on Thermal Cracking of Asphalt Concrete Pavements. J. Assoc. Asph. Paving Technol. 2008, 77, 709-738.

7. Huurman, M.; Mo, L.; Woldekidan, M.F.; Khedoe, R.N.; Moraal, J. Overview of the LOT meso mechanical research into porous asphalt ravelling. In Advanced Testing and Characterization of Bituminous Materials 1; CRC Press: Boca Raton, FL, USA, 2009; pp. 507-517.

8. Kluttz, R.; Jellema, E.; Woldekidan, M.; Huurman, M. Highly Modified Bitumen for Prevention of Winter Damage in OGFCs. In Proceedings of the Airfield and Highway Pavement, Los Angeles, CA, USA, 9-12 June 2013; pp. 1075-1087.

9. Oliviero Rossi, C.; Spadafora, A.; Teltayev, B.; Izmailova, G.; Amerbayev, Y.; Bortolotti, V. Polymer modified bitumen: Rheological properties and structural characterization. Colloids Surf. A Physicochem. Eng. Asp. 2015, 480, 390-397. [CrossRef]

10. Shen, J.; Amirkhanian, S.N.; Xiao, F.; Tang, B. Influence of surface area and size of crumb rubber on high temperature properties of crumb rubber and modified binders. Constr. Build. Mater. 2009, 23, 304-310. [CrossRef]

11. Mashaan, N.S.; Karim, M.R. Investigating the Rheological Properties of Crumb Rubber Modified Bitumen and its Correlation with Temperature Susceptibility. Mater. Res. 2013, 16, 116-127. [CrossRef]

12. Baldino, N.; Gabriele, D.; Oliviero Rossi, C.; Seta, L.; Lupi, F.R.; Caputo, P. Low temperature rheology of polyphosphoric acid (PPA) added bitumen. Constr. Build. Mater. 2012, 36, 592-598. [CrossRef] 
13. Rossi, C.O.; Caputo, P.; Baldino, N.; Szerb, E.I.; Teltayev, B. Quantitative evaluation of organosilane-based adhesion promoter effect on bitumen-aggregate bond by contact angle test. Int. J. Adhes. Adhes. 2017, 72, 117-122. [CrossRef]

14. Rossi, C.O.; Caputo, P.; Baldino, N.; Lupi, F.R.; Miriello, D.; Angelico, R. Effects of adhesion promoters on the contact angle of bitumen-aggregate interface. Int. J. Adhes. Adhes. 2016, 70, 297-303. [CrossRef]

15. Rossi, C.O.; Taltayev, B.; Angelico, R. Adhesion Promoters in Bituminous Road Materials: A Review. Appl. Sci. 2017, 7, 524. [CrossRef]

16. Loeber, L.; Sutton, O.; Morel, J.; Valleton, J.M.; Muller, G. New direct observations of asphalts and asphalt binders by scanning electron microscopy and atomic force microscopy. J. Microsc. 1996, 182, 32-39. [CrossRef]

17. Masson, J.F.; Leblond, V.; Margeson, J. Bitumen morphologies by phase-detection atomic force microscopy. J. Microsc. 2006, 221, 17-29. [CrossRef] [PubMed]

18. Hung, A.M.; Fini, E.H. AFM study of asphalt binder "bee" structures: Origin, mechanical fracture, topological evolution, and experimental artifacts. RSC Adv. 2015, 5, 96972-96982. [CrossRef]

19. Yoon, S.; Bhatt, S.D.; Lee, W.; Lee, H.Y.; Jeong, S.Y.; Baeg, J.O.; Lee, C.W. Separation and characterization of bitumen from Athabasca oil sand. Korean J. Chem. Eng. 2009, 26, 64-71. [CrossRef]

20. ASTM Standard 2005. Standard for Penetration-Graded Asphalt Cement for Use in Pavement Construction, D946-82; ASTM International: Montgomery, PA, USA, 2005.

21. Coppola, L.; Gianferri, R.; Rossi, C.O.; Nicotera, I.; Ranieri, G.A. Structural changes in CTAB/ $\mathrm{H}_{2} \mathrm{O}$ mixtures using a rheological approach. Phys. Chem. Chem. Phys. 2004, 6, 2364-2372. [CrossRef]

22. Angelico, R.; Carboni, M.; Lampis, S.; Schmidt, J.; Talmon, Y.; Monduzzi, M.; Murgia, S. Physicochemical and rheological properties of a novel monoolein-based vesicle gel. Soft Matter 2013, 9, 921-928. [CrossRef]

23. Read, J.; Whiteoak, D. The Shell Bitumen Handbook, 5th ed.; Hunter, R.N., Ed.; Thomas Telford Publishing: London, UK, 2003.

24. Antunes, F.; Gentile, L.; Rossi, C.O.; Tavano, L.; Ranieri, G.A. Gels of Pluronic F127 and nonionic surfactants from rheological characterization to controlled drug permeation. Colloids Surf. B Biointerfaces 2011, 87, 42-48. [CrossRef] [PubMed]

25. Andersen, S.I.; Birdi, K.S. Aggregation of asphaltenes as determined by calorimetry. J. Colloid Interface Sci. 1991, 42, 497-502. [CrossRef]

26. Sheu, E.Y.; Storm, D.A. Colloidal properties of asphaltenes in organic solvents. In Asphaltenes: Fundamentals and Applications; Sheu, E.Y., Mullins, O.C., Eds.; Plenum Press: New York, NY, USA, 1995; Chapter 1.

27. Sirota, E.B. Physical structure of asphaltenes. Energy Fuels 2005, 19, 1290-1296. [CrossRef]

28. Masson, J.F.; Leblond, V.; Margeson, J.; Bundalo-Perc, S. Low-Temperature bitumen stiffness and viscous paraffinic nano-and micro-domains by cryogenic AFM and PDM. J. Microsc. 2007, 227, 191-202. [CrossRef] [PubMed]

29. Pauli, A.T.; Grimes, R.W.; Beemer, A.G.; Turner, T.F.; Branthaver, J.F. Morphology of asphalts, asphalt fractions and model wax-doped asphalts studied by atomic force microscopy. Int. J. Pavement Eng. 2011, 12, 291-309. [CrossRef]

30. Fischer, H.R.; Dillingh, B.; Ingenhut, B. Fast solidification kinetics of parts of bituminous binders. Mater. Struct. 2016, 49, 3335-3340. [CrossRef]

31. Ramm, A.; Sakib, N.; Bhasin, A.; Downer, M.C. Optical characterization of temperature- and composition-dependent microstructure in asphalt binders. J. Microsc. 2016, 262, 216-225. [CrossRef] [PubMed]

32. Yan, K.; Zhang, H.; Xu, H. Effect of polyphosphoric acid on physical properties, chemical composition and morphology of bitumen. Constr. Build. Mater. 2013, 47, 92-98. [CrossRef]

33. Bohlin, L. A Theory of Flow as a Cooperative Phenomenon. J. Colloid Interface Sci. 1980, 74, 423-434. [CrossRef]

34. Winter, H.H. Can the Gel Point of a Cross-linking Polymer Be Detected by the $\mathrm{G}^{\prime}-\mathrm{G}^{\prime \prime}$ Crossover? Polym. Eng. Sci. 1987, 27, 1698-1702. [CrossRef]

35. Rossi, C.O.; Coppola, L.; La Mesa, C.; Ranieri, G.A.; Terenzi, M. Gemini surfactant-water mixtures: Some physical-chemical properties. Colloids Surf. A 2002, 201, 247-260.

36. Coppola, L.; Gianferri, R.; Rossi, C.O.; Nicotera, I. Solution and Liquid-Crystalline microstructures in Sodium Taurodeoxycholate/ $\mathrm{D}_{2} \mathrm{O}$ mixtures. Langmuir 2003, 19, 1990-1999. [CrossRef] 
37. Coppola, L.; Gentile, L.; Nicotera, I.; Rossi, C.O.; Ranieri, G.A. Evidence of Formation of Ammonium Perfluorononanoate $/{ }^{2} \mathrm{H}_{2} \mathrm{O}$ Multilamellar Vesicles: Morphological Analysis by Rheology and Rheo- ${ }^{2} \mathrm{H} N \mathrm{NR}$ Experiments. Langmuir 2010, 26, 19060-19065. [CrossRef] [PubMed]

38. Gabriele, D.; de Cindio, B.; D'Antona, P. A weak gel model for foods. Rheol. Acta 2001, 40, 120-127. [CrossRef]

39. Gentile, L.; Filippelli, L.; Rossi, C.O.; Baldino, N.; Ranieri, G.A. Rheological and H-NMR Spin-Spin relaxation time for the evaluation of the effects of PPA addition on bitumen. Mol. Cryst. Liq. Cryst. 2012, 558, 54-63. [CrossRef]

40. Baldino, N.; Gabriele, D.; Lupi, F.R.; Rossi, C.O.; Caputo, P.; Falvo, T. Rheological effects on bitumen of polyphosphoric acid (PPA) addition. Constr. Build. Mater. 2013, 40, 397-404. [CrossRef]

41. Rossi, C.O.; Caputo, P.; Loise, V.; Miriello, D.; Taltayev, B.; Angelico, R. Role of a food grade additive in the high temperature performance of modified bitumens. Colloids Surf. A Physicochem. Eng. Asp. 2017. [CrossRef]

(C) 2017 by the authors. Licensee MDPI, Basel, Switzerland. This article is an open access article distributed under the terms and conditions of the Creative Commons Attribution (CC BY) license (http:/ / creativecommons.org/licenses/by/4.0/). 